\title{
O litígio estratégico no Sistema Interamericano de Direitos Humanos como forma de combate ao trabalho escravo
}

Strategic litigation in the Inter-American Human Rights System as the use of an instrument to combat slave labor

\section{Thainá Mamede Couto da Cruz \\ Autora \\ thaimamede@gmail.com \\ Pós-graduanda pela PUC-Rio. \\ http://lattes.cnpq.br/5810136004377900}

\begin{abstract}
Carolina de Campos Melo
\section{Orientadora}

Doutora em Direito Internacional pela UERJ. Mestre em Direito pela PUC-Rio. Professora de Direito da PUC-Rio e Coordenadora do NDH/PUC-Rio.
\end{abstract}

\section{Andrea Bandeira de Melo Schettini Coorientadora}

Doutora em Teoria do Estado e Direito Constitucional pela PUC-Rio. Professora de Direito da PUC-Rio e pesquisadora do NDH/PUC-Rio.

\section{Resumo}

Este artigo tem como objetivo expor o litígio estratégico no Sistema Interamericano de Direitos Humanos como instrumento de promoção da justiça social por meio da solidificação da estratégia de governança transnacional para efetivação dos direitos humanos. Desta forma, buscou-se, analisar o ativismo jurídico estratégico promovido no caso Fazenda Brasil Verde vs. Brasil.

Palavras-Chaves: litigância estratégica; trabalho escravo contemporâneo; justiça social.

\begin{abstract}
This article aims to expose the strategic litigation in the Inter-American System as an instrument for the promotion of social justice through the solidification of transnational governance strategy for the realization of human rights. Thus, in particular, to analyze the strategic legal activism promoted in the case of Fazenda Brasil Verde vs. Brazil.
\end{abstract}

Keywords: strategic litigation; slave labor; social justice. 


\section{Introdução}

A partir do século XX, com o final da Segunda Guerra Mundial (1939 - 1945) e as consequentes modificações sociais decorrentes da guerra, o Direito Internacional passou por um processo de expansão onde os Estados reconheceram a necessidade de proteção dos chamados Direitos Humanos. Tal pensamento tem como objetivo evitar novas violações e garantir a proteção dos indivíduos.

Portanto, impulsionado por esses precedentes pós-guerra, dentro desse processo de internalização dos Direitos Humanos, iniciou-se o movimento do Direito Internacional dos Direitos Humanos (DIDH), instituindo dois sistemas de proteção do indivíduo: o sistema global e o sistema regional. O primeiro é formado por instrumentos internacionais e órgãos burocráticos conduzidos pela ONU. Por outro lado, o segundo tem por objetivo internalização dos direitos humanos no plano regional, subdividido em três grandes sistemas, como o Sistema Europeu de 1950, o Americano de 1969 e o Africano de 1981.

Os sistemas regionais complementam o sistema global, tendo em conta que possuem o mesmo objetivo de proteção do indivíduo e o combate às violações de direitos humanos. Destaca-se que vige internacionalmente o princípio pro persona, sendo assim, se o indivíduo tiver algum direito violado, ele pode optar pelo sistema que mais lhe beneficie.

Com efeito, percebeu-se a necessidade de avaliar a ferramenta utilizada pelos atores sociais dentro do Sistema Internacional, objetivando pressionar os Estados a internalizarem os direitos previstos nas normas, uma vez que o Estado sendo parte de um Sistema de Proteção de Direitos Humanos deve aceitar, empregar e impulsionar os preceitos internacionais de garantias. Tal ferramenta é conhecida como litígio estratégico, na qual corresponde a utilização do espaço judicial como arena de deliberação política, a fim de oportunizar o debate público acerca de tema atrelado a Direitos Humanos.

\section{A litigância estratégica}

É necessário destacar que há diversas nomenclaturas ao litígio estratégico, expressões como "litígio de impacto", "litígio paradigmático", "litígio de caso-teste", "advocacia de 
impacto", "litígio de interesse público", "litígio das causas justas" e entre outros, principalmente na literatura americana (IHRLG, 2001, p.82) ${ }^{1}$.

A litigância estratégica consiste em um mecanismo chave no sistema moderno de justiça, de modo que viabiliza e fomenta a discussão entre os órgãos do Estado, os representantes políticos e a sociedade civil no plano doméstico e internacional. Sendo assim, parte-se do pressuposto que o litígio estratégico é um meio de potencial modificação da realidade de violações. Desta forma, Cardoso relata que objetivo desses atores sociais é se colocarem como agentes de um processo normativo transnacional (2012, p. 41).

Santos (2017, p. 28) observa que o ativismo jurídico transnacional seria um tipo de ativismo focado na ação legal engajada através das cortes internacionais e instituições quase judiciais para fortalecer as demandas dos movimentos sociais; realizar mudanças legais e políticas internas; reestruturar ou redefinir direitos; e/ou pressionar os Estados a cumprirem as normas internacionais e internas dos direitos humanos. Sendo assim, há um processo de empoderamento das vítimas, onde as pessoas envolvidas deixam de ser apenas sujeitos passivos no processo.

Desta forma, pode-se compreender que o ativismo jurídico transnacional consiste nessa tentativa do uso do litígio de impacto para (re)discutir políticas internas e reestruturar os direitos, provocando o âmbito das arenas das cortes internacionais e/ou os sistemas interamericanos de direitos (CRUZ, 2018, p.40). No entanto, tal ferramenta deve ser utilizada com cautela, visto que uma demanda sem um preparo ou sem um propósito específico e/ou complementares pode levar a consequências indesejadas e o não alcance dos objetivos traçados no litígio estratégico.

Podemos observar que um dos efeitos mais evidentes e problemáticos é o "filtro negativo" ${ }^{2}$ de casos realizados pela Comissão Interamericana de Direitos Humanos (CIDH). Tal efeito pode ser traduzido por meio da metáfora do funil do Sistema Interamericano, onde há uma grande demanda de peticionamento na Comissão, mas nem todos os casos passam pelo crivo do controle de admissibilidade da $\mathrm{CIDH}$, e menores ainda são os números de casos enviados à Corte IDH.

Destaca-se que não há uma transparência da CIDH no processo de judicialização dos casos até mesmo porque não é possível o acesso aos documentos dos peticionários, apenas das

\footnotetext{
${ }^{1}$ Tradução livre. "Strategic litigation is but one of a number of terms used to refer to the type of activity described. Terms such as "impact litigation" and "test litigation" are sometimes used interchangeably with strategic litigation".

2 A expressão "filtro negativo" corresponde a forma de representar a atuação seletiva da CIDH no processo de triagem das petições que são encaminhadas e admitidas para análise pelo órgão. 
decisões. As razões do filtro negativo é uma temática muito importante para o desenvolvimento do litígio estratégico no Sistema Interamericano. Apesar das críticas, é inegável para a doutrina a atuação politizada e seletiva da CIDH, como também a falta de recursos repassados ao órgão.

Para Abramovich, o caráter político do Sistema Interamericano é muito relevante enquanto mecanismo estratégico para o fortalecimento das instituições democráticas na América Latina, especialmente, no tocante para a superação das desigualdades sociais. Vejamos:

(...) além da consolidação da jurisprudência e do desenvolvimento de seu sistema de petições individuais, o SIDH deve considerar seu papel político, colocando em foco os padrões estruturais que afetam o exercício efetivo dos direitos pelos grupos subordinados da população (ABRAMOVICH, 2009, p. 29).

Por todo exposto, as definições de litígio estratégico vão ser moldadas conforme as atividades desses atores sociais, por isso denominada como um "discurso-prática" por Evorah Cardoso (2012, p. 40). Assim, exercendo um papel de protagonismo no SIDH.

Percebe-se, que a atuação dos atores não-estatais é fundamental para avaliação dos casos de litígio. Por isso, declara Villarreal (2007, p.22) que alguns grupos internacionais de advogados de interesse público consideram que o melhor momento para recorrer ao litígio estratégico são nas seguintes situações: (i) se o direito não for observado; (ii) se houver discordância com padrões internacionais, buscando as melhores práticas para esclarecer a lei existente; (iii) quando há aplicação errada e arbitrária da lei; (iv) aplicação dos direitos econômicos, sociais e culturais vs. civis e políticos dentre outros.

Nessa seara, a autora utiliza como referência o Handbook for legal professionals and activits $^{3}$, elaborado pela Public Interess Law Initiative in Transitional Societies da Columbia University School of Law, para afirmar outros possíveis momentos para o litígio: (i) quando boas leis são letra morta; (ii) quando a aplicação do direito, seja pelas autoridades ou até mesmo pelos próprios tribunais é incerta e/ou imprevisível, isto é, quando é impossível saber com certeza o caminho; (iii) quando as restrições estão estruturalmente imersas na lei, ou seja, a fonte das violações é a própria lei; (iv) a existência de standard de internacionais que possa ser utilizado pelos Estados como padrão e; (v) reconhecimento do direito em sentença.

\footnotetext{
${ }^{3}$ Para mais informações, ver o documento no site. Disponível em: <https://www.pilnet.org/publicinterest-law-resources/35-pursuing-the-public-interest-a-handbook-for-legal.html>. Acesso em: 05 mai. 2018.
} 
Montoya (2008, p.156) afirma que para o desenvolvimento do litígio de alto impacto é necessário a reunião de três componentes compreendidos em: judicial, político e comunicativo. O componente judicial é justificado na medida em que é identificada a problemática social que envolve uma violação da lei ou uma ameaça latente de danos, na qual se pode responsabilizar o Estado por aqueles direitos sociais e coletivos. Além do mais, a equipe estratégica deve possuir uma interdisciplinaridade de modo a empoderar aquela comunidade dos seus direitos básicos, visando garantir a participação comunitária na construção do caso.

Já o segundo componente, político, corresponde ao alcance de uma mudança no campo específico de um programa ou um projeto governamental, como também a capacidade de influir com poder de decisão. Por último, o componente comunicativo, insta transmitir o planejamento idealizado e ao mesmo tempo propõe influenciar e pressionar a opinião pública.

Importante destacar que autores como James L. Cavallaro e Stephanie Erin Brewer defendem esses caminhos alternativos que os litigantes podem utilizar para promover a justiça social através da litigância no Sistema Interamericano (2008, p. 86). Argumentam que os advogados de direitos humanos promoverão melhor tais direitos quando usarem a litigância supranacional como uma ferramenta subsidiária a fim de apoiar os esforços estratégicos liderados por movimentos sociais internos, papel esse que pode, frequentemente, conduzir à inserção estratégica de reivindicações ligadas aos Direitos Econômicos, Sociais e Culturais (DESC) dentro da estrutura de violações a direitos civis e políticos. Afirmam que, com frequência, esse é o caso dos litígios ajuizados perante a Corte Interamericana de Direitos Humanos (CAVALLARO; BREWER, 2008, p. 85).

Portanto, aqueles que utilizam a litigância como principal veículo para a promoção dos direitos humanos, devem reconhecer e apoiar a mobilização de movimentos sociais, sociedade civil e mídia, considerando que objetivam promover justiça social. Como é cediço, muitos, senão a maioria dos advogados de direitos humanos, já reconhecem que a litigância possui maior potencial de impacto quando ocorre em conjunto com a mobilização promovida pelos movimentos sociais, com cobertura pela mídia e com outras formas de pressão doméstica e internacional (CAVALLARO; BREWER, 2008, p. 88).

Cavallaro e Schaffer explicam essa correlação, vejamos:

A sociedade civil pode procurar a efetivação de direitos individuais através do recurso aos mecanismos de proteção aos direitos humanos do Sistema Interamericano de Proteção aos direitos humanos; a seu turno, o sistema precisa do apoio da sociedade civil para sua legitimidade. Governos fornecem os recursos necessários para manter o sistema interamericano funcionando e elegem os indivíduos que vão servir como comissionados ou juízes nos seus 
órgãos de monitoramento; mas essas instituições também dependem da aceitação voluntária da sua autoridade e participação com boa-fé nas regras de engajamento estabelecidas para que serem efetivas. E essas instituições que compõem o sistema têm a autoridade para resolver demandas e emitir decisões requerendo a ação tanto dos governos quanto de atores da sociedade civil; mas essa autoridade depende da percepção desse último grupo de que ela é exercida de modo razoável e apropriado (CAVALLARO; SCHAFFER.2004, p. 220-221 apud BERNARDES, 2011, p. 140).

Bernardes (2011, p. 140) assevera que não há dúvidas entre os que militam no SIDH de que a litigância estratégica constitui uma ferramenta importante para promoção de direitos humanos. A autora relata que ao longo do contencioso internacional e das muitas trocas entre atores estatais e da sociedade civil de diferentes nacionalidades, determinadas práticas são criticadas, novos repertórios de ação são adquiridos e a assimetria de poder entre Estado e indivíduo pode ser mitigada. Tais efeitos podem resultar de genuínos processos de aprendizado e consolidação democrática que podemos chamar de processos de desenvolvimento de consciência (awareness raising) ou de estratégias de pressão política, criando-se constrangimentos (embarassement power) para Estados que se dizem democráticos.

Essa perspectiva de trazer a sociedade civil para o SIDH constitui uma estratégica dos atores sociais, de modo que a sociedade possa exigir seus direitos fundamentais que foram violados. Por isso, enfatiza Bernardes, o SIDH proporciona as bases institucionais para a construção de uma esfera pública transnacional que pode contribuir para a ampliação da democracia brasileira (2011, p. 136).

\section{Sistema Interamericano de Direitos Humanos}

A Organização dos Estados Americanos ${ }^{4}$ (OEA) foi o organismo regional que estruturou a proteção dos direitos humanos nas Américas, tendo como objetivo alcançar "uma ordem de paz e de justiça, para promover sua solidariedade, intensificar sua colaboração e defender sua soberania, sua integridade territorial e sua independência" ${ }^{5}$. Concomitantemente ao ano da criação da OEA, foi aprovada a Declaração Americana de Direitos e Deveres do Homem de 1948 (Declaração Universal de Direitos Humanos), primeira declaração de Direitos Humanos aprovada por órgãos internacionais.

\footnotetext{
${ }^{4}$ Durante a IX Conferência Internacional Interamericana de Estados Americanos, realizada em Bogotá em maio de 1948.

${ }^{5}$ Artigo $1^{\circ}$ da Carta da OEA.

DIGNIDADE RE-VISTA | ISSN2525-698X| 2020 | V. V | N. 9 ESP | Direitos Humanos, direitos para todos: pensando a igualdade material dos direitos. Pastoral Universitária Anchieta PUC-RIO.
} 
A Declaração formou a primeira base normativa de proteção aos direitos humanos de caráter geral no sistema e continua sendo um instrumento de importância e expressão regional, especialmente para os Estados que não são parte da Convenção Americana (MAZZUOLI, 2013, p. 926). A Declaração se destacou de outros instrumentos internacionais de direitos humanos, pois não definiu apenas os direitos, mas os deveres dos cidadãos ${ }^{6}$. No entanto, vale dizer que a declaração não é considerada um tratado internacional, mas fonte de obrigação para os Estados e membros da OEA, conforme Opinião Consultiva da Corte IDH $^{7}$.

Em 1969, os Estados Americanos adotaram em São José, Costa Rica, a Convenção Americana de Direitos Humanos (CADH), também conhecida como Pacto de São José, que entrou em vigor somente em 1978, após alcançar o número mínimo de onze ratificações estatais. A Convenção Americana estipulou também a criação da Corte Interamericana de Direitos Humanos (Corte IDH), fundada um ano depois, como um órgão jurisdicional do SIDH, responsável por julgar as violações de direitos humanos perpetradas pelos Estados que ratificaram sua competência.

Abramovich (2009, p.8) afirma que o desenvolvimento do Sistema Interamericano não foi linear, sendo dividindo em quatro fases: $1^{\mathrm{a}}$ fase da década de 1970 a $1980,2^{\mathrm{a}}$ fase do final da década de 1980 até o início da década de 1990, $3^{\text {a }}$ fase nos anos 2000 e por fim, a $4^{\text {a }}$ fase de desafios e crise institucional. Atualmente, o SIDH se encontra num período de fortes debates, tendo em vista o novo cenário político regional de democracias deficitárias e excludentes.

Na primeira fase, o SIDH desempenhou um papel ainda que sutil de crítica e combate às graves violações de direitos humanos perpetuadas durante as ditaduras militares instauradas na América Latina (SCHETTINI; FERREIRA, 2016. p.154). Dentre as denúncias estão as práticas de tortura, desaparecimento forçado, prisão arbitrária e assassinato.

A segunda fase foi marcada pela transição dos regimes autoritários para sistemas políticos democráticos. Nesse contexto, foi possível ao SIDH delinear os princípios fundamentais sobre o direito à justiça, à verdade, e a reparação de graves violações em massa e sistemáticas de direitos humanos (SCHETTINI; FERREIRA, 2016. p.154). Ao longo dos anos 2000, na terceira fase, foi o momento de maior estabilidade, onde foi sistematizado o papel subsidiário do SIDH de proteção dos direitos humanos à esfera interna dos Estados.

6 Declaração Americana dos Direitos e Deveres do Homem, 1948. Disponível em: $<$ https://www.cidh.oas.org/basicos/portugues/b.Declaracao_Americana.htm>. Acesso em: 12 mai. 2018.

7 CORTE IDH. Interpretação da Declaração Americana dos Direitos e Deveres do Homem. Opinião Consultiva OC-10/89, parágrafo 42.

DIGNIDADE RE-VISTA | ISSN2525-698X| 2020 | V. V | N. 9 ESP | Direitos Humanos, direitos para todos: pensando a igualdade material dos direitos. Pastoral Universitária Anchieta PUC-RIO. 
Hoje estamos na quarta fase, momento de forte crise institucional, onde países como Bolívia, Equador e Venezuela começaram em 2010 a criticar abertamente o Sistema Interamericano, especialmente da atuação da CIDH. Eles afirmam que seria um órgão tendencioso à política norte-americana, uma vez que a sede da Comissão é localizada em Washington, capital dos Estados Unidos, país que não ratificou a $\mathrm{CADH}$ e nem aceitou a jurisdição da Corte IDH; o fato de os principais financiadores da CIDH serem Estados europeus e organismos e fundações de cooperação internacional financiadas por Estados observadores que não ratificaram a $\mathrm{CADH}$; e o fato de supostamente não alcançar as principais demandas e transformações latino-americanas (PRONER, 2012).

Ademais, após a denúncia voluntária do instrumento normativo da OEA (Carta da OEA de 1948) pela Venezuela e seu consequente pedido de desligamento em 2012 (oficializado em 27/04/2019, após 2 anos de aviso prévio conforme previsão da OEA), esse conflito se expandiu, resultando na realização de um processo oficial de Reflexão sobre o Funcionamento da CIDH para o fortalecimento do $\mathrm{SIDH}^{8}$ coordenado pela Assembleia Geral da OEA.

Destaco que o Conselho Permanente da OEA aprovou a Resolução CP/RES. 1133 $(2244 / 19)^{9}$ que condena veementemente as graves e sistemáticas de violações de direitos humanos na Venezuela, inclusive o uso da tortura e prática de detenções ilegais e arbitrárias, negação de direitos e necessidades básicas, em relação à saúde, alimentação e educação. Ademais, reafirmar que venezuelanas e venezuelanos que sofrem a perseguição do regime.

Apesar de toda essa questão de legitimidade do SIDH, Abramovich (2009, p.7) afirma que após a aceitação da competência da Corte IDH e a atribuição à CADH a hierarquia constitucional ou superior às leis ordinárias em seus sistemas jurídicos, os advogados, os juízes, os operadores do direito, os funcionários e ativistas sociais aprenderam muito mais sobre a lógica de funcionamento do SIDH e começaram a utilizá-lo já não mais de maneira excepcional ou seletiva; como também começaram a citar suas decisões e argumentar com seus precedentes nos tribunais locais e em debates sobre políticas públicas. Com isso, a jurisprudência do SIDH começou a ser aplicada gradualmente nas decisões dos tribunais constitucionais e das cortes supremas nacionais e, nos últimos tempos, ainda que de maneira incipiente, na formulação de algumas políticas estatais. Esse processo de incorporação do direito internacional dos direitos humanos no âmbito nacional produziu importantes mudanças institucionais.

\footnotetext{
8 OEA. Sobre 0 fortalecimento. Disponível em: <http://www.oas.org/pt/cidh/fortalecimento/consulta2013.asp>. Acesso em: 05 mai. 2018.

${ }^{9}$ OEA. Conselho Permanente da OEA aprova resolução sobre a situação dos direitos humanos na Venezuela. Disponível: <https://www.oas.org/pt/centro_midia/nota_imprensa.asp?sCodigo=P058/19>. Acesso em: 10 mar. 2019.
} 


\section{Âmbito de atuação dos órgãos do Sistema Interamericano}

O Sistema Interamericano divide-se em dois órgãos: a Comissão Interamericana de Direitos Humanos (CIDH), criada em 1959 e a Corte Interamericana de Direitos Humanos (Corte IDH), de 1978. Ambos foram decisivos na proteção das vítimas das ditaduras latinoamericanas. E ainda hoje cumprem um papel crucial diante dos graves casos de violação dos direitos humanos.

\section{Comissão Interamericana de Direitos Humanos}

A CIDH, conforme previsão do artigo 1 do Estatuto da CIDH, é um "órgão da Organização dos Estados Americanos criados para promover a observância e a defesa dos direitos humanos e para servir como órgão consultivo da Organização nesta matéria. "10. No tocante a estrutura, a Comissão está localizada em Washington, Estados Unidos, integrada por sete membros indicados pelos países membros da OEA e eleitos pela Assembleia Geral da OEA, para um mandato de quatro anos, podendo ser reeleito por um período adicional. Os membros elegem anualmente um Presidente e dois Vice-presidentes, além de realizar a cada ano dois períodos ordinários de sessões, e entre um e três períodos extraordinários de sessões ${ }^{11}$.

Em relação as suas atribuições estão previstas em seus instrumentos legais como a $\mathrm{CADH}$, o estatuto e o regulamento, o estímulo da consciência dos direitos humanos no continente americano e análise de casos individuais, os quais após uma revisão preliminar, podem ser submetidos à Corte, a publicação de informações especiais sobre a situação dos direitos humanos em um Estado específico; a realização de vistoria in loco aos países para analisar em profundidade a situação geral, e/ou para investigar em situação particular, com posterior preparação do respectivo relatório, fazer recomendações aos Estados membros da OEA, a adoção de medidas cautelares, solicitação de opiniões consultivas à Corte, dentre outros.

Uma das principais funções exercidas pela CIDH é o recebimento de denúncia, ou seja, o sistema de peticionamento do SIDH, onde pessoas ou organizações questionam a ocorrência

10 Estatuto da Comissão Interamericana de Direitos Humanos. Disponível em: <http://www.cidh.org/basicos/portugues/t.estatuto.cidh.htm>. Acesso em: 20 agos. 2019. ${ }_{11}$ OEA. Sobre a estrutura do SIDH. Disponível em: <http://www.oas.org/pt/sobre/comissao_direitos_humanos.asp>. Acesso em: 05 mai. 2018. 
de violações de direitos humanos, por parte dos Estados-parte da $\mathrm{OEA}^{12}$, com fundamento na Convenção ou em outros instrumentos normativos do sistema, apresentando uma denúncia por meio do instrumento de petição.

Bernardes (2011, p. 145) ressalta que o recurso ao SIDH acontece hoje pelo o que conhecemos como advocacia de impacto ou litigância estratégica, visto que as organizações da sociedade civil especializada nesse tipo de litígio não remetem qualquer caso à CIDH, e sim optam por demandas estratégica. Além disso, informa que são levadas petições nos três seguintes critérios: (i) violações sistemáticas de violações no âmbito interno de um Estado; (ii) não possuem jurisprudência sedimentada no SIDH e que possam colaborar com a construção de novos padrões internacionais de proteção de direitos humanos e (iii) questões humanitárias, onde a vítima encontra-se em extrema vulnerabilidade.

Conforme o artigo 46 (1) da Convenção, para que a Comissão possa aceitar uma denúncia é necessário que haja o esgotamento dos recursos da jurisdição interna, tendo em vista o caráter subsidiário do sistema interamericano tem em relação à proteção que deve ser garantida pelos Estados, exceto aqueles casos em que não existir, na legislação nacional, o devido processo legal para a proteção do direito violado; em que não se houver permitido à suposta vítima o acesso à justiça; ou quando houver uma demora injustificada de decisão. Desta forma, o Estado deve investigar e sancionar toda violação dos direitos reconhecidos pela Convenção e buscar o restabelecimento, se possível, do direito violado (CRUZ, 2018, p. 34).

Note-se que também há outros requisitos de admissibilidade, como o $\operatorname{prazo}^{13}$ de apresentação da denúncia à CIDH, sendo assim, não pode ter passado os seis meses da ciência da violação. E, por fim, o último requisito para admissibilidade do recurso é que não se tenha recorrido a nenhum outro órgão internacional que possua procedimento litigioso em paralelo, o que chamamos de litispendência ${ }^{14}$ (CRUZ, 2018, p. 34).

A apreciação das petições pela CIDH são recebidas por chegada, salvo naqueles casos de prioridade, especialmente se houver vítima muito jovem ou idosa, portadora de enfermidade terminal, de ter riscos da aplicação de pena de morte, lhe foram concedidas medidas cautelares, se a vítima estiver privada de liberdade, ou ainda em casos que a decisão, por alterar a legislação

\footnotetext{
$12 \mathrm{O}$ sujeito passivo do SIDH, tanto na CIDH quanto na Corte IDH é sempre um Estado e não um indivíduo, uma vez que o objetivo do sistema é proteger a vítima.

${ }_{13}^{13}$ De acordo com o artigo 46 (1) (b) da Convenção.

${ }^{14}$ De acordo com o artigo 46 da Convenção.
}

DIGNIDADE RE-VISTA | ISSN2525-698X| 2020 | V. V | N. 9 ESP | Direitos Humanos, direitos para todos: pensando a igualdade material dos direitos. Pastoral Universitária Anchieta PUC-RIO. 
e as práticas do Estado, poderia reparar graves problemas estruturais sérios e evitar múltiplas petições das violações nas práticas do Estado $^{15}$.

Portanto, declarada admissível, a CIDH inicia a investigação sobre os fatos do peticionário, podendo solicitar informações e documentos adicionais ao Estado ou às vítimas e realizar oitivas tanto do peticionário quanto do governo. Portanto, sendo declarada admissível a petição, a CIDH elabora um informe de admissibilidade e aquela petição transforma-se em um caso. No entanto, se declarada inadmissível pelos fatos alegados ou naqueles casos em que o processo fica parado por longos períodos, em regra, o processo é arquivado (CRUZ, 2018, p.35). Desta feita, havendo admissibilidade do caso, a Comissão dá início a fase do mérito, uma vez que já foram apresentadas informações e defesas de ambos os lados e passa-se a análise da Comissão para averiguação da existência de violação de direitos humanos.

É necessário destacar um aspecto importante durante esse período na Comissão, relativa à possibilidade de adoção de soluções amistosas (artigo 40 do Regulamento da CIDH), isto é, um acordo entre as partes litigantes que interrompe o procedimento. Para isso, há a necessidade de aquiescência das vítimas, se realizado, a CIDH publica o acordo (artigo 41 do seu Regulamento).

Consequentemente, há duas saídas para decisão da CIDH: uma pela negativa e a outra pela ocorrência da violação. A CIDH pode emitir recomendações para o Estado violador, para que, na medida do possível, restabeleça os direitos violados, impeça a realização de novas violações e investigue e repare às vítimas.

Caso o Estado não cumpra com as recomendações, a CIDH poderá publicar um relatório de forma pública para pressionar o país e/ou submeter à Corte IDH. Por oportuno, registro que há Estados que não aceitaram a competência da Corte, logo, para esses países resta apenas a publicação do relatório sobre a responsabilidade das violações. Entretanto, naqueles países que aceitaram a competência da Corte IDH, a Comissão poderá submetê-lo à sua jurisdição.

Uma característica importante do relatório da Comissão é que no primeiro momento ele é enviado ao Estado de maneira reservada, permitindo que o Estado não sofra nenhum constrangimento internacional. Porém, se não for cumprido em três meses, a CIDH elabora um novo informe de modo público e encaminha a Corte IDH.

\footnotetext{
${ }^{15}$ IJRC (International Justice Resource Center). Atuação perante o Sistema Interamericano: Manual para advogados e ativistas, 2014. p. 19 Disponível em: <http://ijrcenter.org/wpcontent/uploads/2014/03/Manual-Atuacao-perante-o-Sistema-Interamericano-2014.pdf>. Acesso em: 15 mai. 2018.
} 
A segunda principal função desempenhada pela SIDH diz respeito à adoção de medidas cautelares mediante a CIDH, requisitos esses definidos no artigo 25 do Regulamento da CIDH. Nos casos de gravidade e urgência, é possível a adoção de medidas cautelares com o objetivo de prevenir danos irreparáveis às pessoas ou ao objeto relativo a uma petição ou caso pendente. Neste caso, não se exige o esgotamento de recurso, porém permanece a regra da subsidiariedade. A Comissão desempenha funções perante a CIDH, tendo em vista que submete ao entendimento da Corte, casos nos quais os Estados não tenham cumprido as recomendações elaboradas por essa Comissão.

\section{Corte Interamericana de Direitos Humanos}

A Corte Interamericana de Direitos Humanos consiste em um órgão jurisdicional do SIDH. Trata-se de uma instituição autônoma da OEA cujo objetivo é a aplicação e interpretação da $\mathrm{CADH}$ e de outros tratados concernentes aos direitos humanos.

Este órgão é composto por sete juízes, nacionais dos Estados membros da OEA, com mandato de seis anos, podendo ser reconduzidos uma vez mais pelo mesmo período. A escolha é realizada por votação secreta por maioria absoluta de votos durante a Assembleia da OEA, dentre os três candidatos indicados para o cargo de Juiz do Estado-partes da CADH. A Corte é um tribunal não permanente, que se reúne por alguns períodos ordinários de sessões e dois extraordinários ao longo do ano, exercendo duas competências distintas: a consultiva e a contenciosa.

A competência consultiva está prevista na disposição do artigo 64 da $\mathrm{CADH}$, onde a CIDH, os Estados membros da OEA, parte ou não da CADH, podem consultar a Corte IDH solicitando uma interpretação sobre a norma, recebendo o nome de Opiniões Consultivas. Por sua vez, a função contenciosa diz respeito ao conhecimento dos casos individuais em que se alegam violações de direitos humanos consagrados em instrumentos normativos por Estadoparte. Segundo Flávia Piovesan (2013, p. 139), a competência contenciosa tem caráter jurisdicional, referente à solução de controvérsias que se apresentem acerca da interpretação ou aplicação da própria convenção.

A competência contenciosa da Corte está respaldada nos artigos 61, 62 e 63 da CADH. É válido destacar que conforme o artigo 61 da Convenção Americana, apenas a CIDH e os Estados parte de tal convenção tem legitimidade para submeter um caso à decisão da Corte. Da 
mesma forma, para que a Corte possa conhecer de qualquer caso, é necessário que sejam esgotados os processos previstos nos artigos 48 a $50^{16}$.

Vale mencionar que essa competência desenvolve-se em três funções, tais como: análise do caso de violação de direitos humanos, supervisão do cumprimento da sentença e adoção de medidas provisórias. A primeira corresponde a análise do caso submetido à Corte para investigar e consequentemente informar se o Estado tem ou não responsabilidade internacional pela suposta violação. Entretanto, antes de averiguar se o Estado possui a responsabilidade, a Corte faz um juízo de admissibilidade, mérito e as reparações.

Destaco que em 2009, com o objetivo de fortalecimento da CIDH foi feita uma mudança no Regulamento da Corte IDH, permitindo um papel mais ativo das vítimas e dos peticionários dos casos, embora ainda caiba à CIDH iniciar o procedimento perante a Corte.

Pode acontecer que as vítimas não tenham representação legal para o litígio perante a Corte, à vista disso, o Regulamento criou a figura do Defensor Interamericano ${ }^{17}$, podendo ser uma pessoa ou grupo de pessoas para defesa daquele caso específico. Ou seja, há uma valorização do papel das vítimas no procedimento internacional. Infelizmente, esse processo ainda é custoso, devido ao deslocamento para a sede da Comissão ou da Corte, o envio de materiais e todos os trâmites processuais para a possível análise.

A segunda função refere-se a supervisão do cumprimento de sentença de acordo com o artigo 65 da $\mathrm{CADH}$, onde a Corte fiscaliza a determinação adotada, solicitando informações às vítimas e ao Estado sobre as atividades desenvolvidas ou não. E, posteriormente, encaminha essa resposta para a Assembleia Geral da OEA

Já a última função é a implementação de medidas provisórias. Segundo o artigo 63 da $\mathrm{CADH}$ nos casos de extrema gravidade e urgência, quando se faça necessário evitar danos às pessoas, a Corte poderá adotar medidas provisórias, do mesmo modo, pode ditar medidas provisórias a pedido da CIDH.

Em suma, o caminho percorrido pelo SIDH demonstrou avanços e resultados significativos. Além disso, potencializou a atuação dos indivíduos e das organizações não

\footnotetext{
${ }^{16}$ Artigo 61.2 da CADH.

${ }_{17}$ A figura do Defensor Público Interamericano foi incorporada ao sistema interamericano por meio de uma reforma estrutural, na qual as vítimas passaram a ter locus standi no procedimento perante a Corte Interamericana. Para mais informações, acessar o Acordo de Cooperação Geral entre a Secretaria Geral da OEA e a AIDEF, disponível em: <https://www.mpd.gov.ar/users/uploads/1402684164Acuerdo\%20final\%200EA\%20AIDEF.pdf> e Acordo de Entendimento entre a CIDH e a Associação Interamericana de Defensorias Públicas <https://www.mpd.gov.ar/index.php/component/content/article/126-internacional/aidef/470reglamento-unificado-aidef-ante-cidh-y-corteidh-aprobado-en-antigua-guatemala-el-7-de-junio-de2013.html? ltemid=101>. Acesso em: 12 maio 2018.
} 
governamentais na esfera de litigância internacional. Vale destacar o espaço aberto para diálogo entre as vítimas, organizações sociais e governos, sendo expressivo o crescimento do número de usuários do SIDH.

\section{Do litígio estratégico no Sistema Interamericano de Direitos Humanos}

Após termos estudado a origem e o funcionamento do SIDH, a partir de agora analisaremos como funciona o litígio de impacto dentro da arena do Sistema Interamericano. Sendo assim, este tópico será dividido em duas partes: na primeira trabalharemos a atuação dos atores sociais na promoção da justiça social, enquanto que na segunda, abordaremos a divisão de fases do litígio internacional proposta pela autora Evorah Cardoso.

\section{Das etapas do litígio estratégico no SIDH}

Cardoso elucida o litígio estratégico no SIDH como um ciclo ${ }^{18}$ dividido em quatro etapas que envolve desde o momento da escolha do caso até a implementação das decisões pela Corte IDH. A primeira etapa é o momento em que os casos são escolhidos pelos atores sociais de acordo com os objetivos e estratégias daquele litigante. Muitas das vezes, a escolha se dá por uma parceria entre as ONGs maiores com as menores, de forma que as maiores levam os casos coletados pelas menores para o Sistema Interamericano. Esse movimento acontece porque essas as maiores possuem maior aptidão e conhecimento especializado no sistema resultando assim em uma cooperação proveitosa para ambas as partes, dado que a ONG maior pode acompanhar com mais afinco o trâmite no caso, bem como pode impulsar melhor o andamento do processo, enquanto que a ONG local cuida do atendimento à vítima e promove a divulgação do tema no âmbito doméstico.

Outrossim, o sistema também pode ser acionado por meio de advogados particulares, entretanto, o número de atores com esse enfoque é bem reduzido, uma vez que grande é dificuldade encontrada no momento do financiamento do processo ainda é extremamente custoso, tendo em vista a necessidade de deslocamento para a sede da Comissão ou da Corte,

\footnotetext{
${ }^{18}$ A organização do manual da ONG Internacional Interights sobre litigio estratégio parece sugerir a mesma abordagem, conforme os tópicos de seu índice ("case selection", "the process of strategic litigation planning", "case management and strategy", "post-litigation implementation").

ERRC, Acesso em: 15 abr. 2018.

DIGNIDADE RE-VISTA | ISSN2525-698X| 2020 | V. V | N. 9 ESP | Direitos Humanos, direitos para todos: pensando a igualdade material dos direitos. Pastoral Universitária Anchieta PUC-RIO.
} 
de envio de materiais e de todos os demais recursos fundamentais para o trâmite adequado dos casos.

Bernardes (2011, p. 145) afirma que, em geral, são enviados à CIDH petições selecionadas a partir de três critérios principais: (i) casos que retratem cabalmente padrões sistemáticos de violação de direitos humanos internamente; (ii) casos que levantem temas sobre os quais a Corte IDH ou a CIDH não tenham ainda se pronunciado claramente, visando colaborar com a construção de novos padrões internacionais de proteção dos direitos humanos e; (iii) casos humanitários, em que a situação de extrema vulnerabilidade da vítima justifica o litígio, ainda que não se produza nenhum dos outros efeitos mencionados.

Em suma, Bernardes destaca que é realizada uma avaliação estratégica à luz do contexto político-jurídico do país e o próprio objetivo no SIDH. Ressalto que, normalmente, estratégias que obtém maiores resultados são aquelas que acompanham um processo de mobilização e ativismo político dos protagonistas. Portanto, a estratégia de impacto parte da identificação de uma problemática social e como processo de intervenção se esforça a buscar uma solução integral através de componentes interdisciplinares e interrelacionados (CRUZ, 2018, p. 147).

A Comissão corresponde a segunda etapa do litígio estratégico onde há o recebimento da denúncia de violações de direitos humanos previstos na $\mathrm{CADH}$ ou em outros instrumentos normativos do SIDH, cometidas por Estados-parte da OEA. Ato contínuo, é realizada a análise dos requisitos formais para sua admissibilidade, e sendo declarada admissível, a CIDH inicia a investigação sobre os fatos, podendo solicitar informações e documentos adicionais.

Não se sabe os critérios utilizados pela Comissão para o recebimento dos casos, bem como sobre a submissão do caso à Corte IDH. No entanto, não se pode negar que a Comissão tem realizado boas soluções amistosas entre vítimas e Estados, por meio de medidas de impacto coletivo e muitas vezes alcançando promulgação de leis ou alterações políticas de direito humanos na jurisprudência doméstica do país violador. Ademais, quando não realizada a solução amistosa, a Comissão com base no artigo 50 da $\mathrm{CADH}$, redigirá um relatório de mérito $^{19}$ atribuindo responsabilidade do Estado pela violação de direitos humanos, expondo o Estado aos efeitos chamado de power of shaming ou de tematização doméstica. Todavia, se o objetivo da litigância for atingir a formação de um precedente, de modo que possa influenciar e restringir outros casos futuros ou países da região, os representantes das vítimas deverão agir com a finalidade do caso ser encaminhado à Corte IDH.

\footnotetext{
${ }^{19}$ Apesar do Relatório de mérito atribuir responsabilidade ao Estado, ele não possui caráter vinculante, ou seja, não tem caráter obrigatório.
} 
A terceira fase diz respeito aos diferentes procedimentos e mecanismos de participação estratégica dos atores não estatais na decisão da Corte IDH, de sorte que os atores não estatais podem apresentar demandas de maneira autônoma, não necessariamente sendo parte da demanda. No entanto, destaco que essa atuação estratégica também inclui a participação da vítima - após reforma de 2000 - como parte do processo podendo atuar de maneira diferenciada dos próprios representantes com o fito de lograr êxito na demanda.

Observamos que no tópico do funcionamento da Corte IDH que esse órgão possui duas competências principais, a consultiva e a contenciosa. As opiniões consultivas interpretam direitos da $\mathrm{CADH}$ e de outros tratados em determinadas situações hipotéticas apresentados em consulta à Corte IDH, ou ainda, quando solicitados por algum Estado, as opiniões consultivas analisam a compatibilidade da legislação doméstica a essa normativa internacional. Nestes casos, não há partes em litígio, no entanto, a interpretação dada pela Corte pode servir como base para um caso contencioso, formando precedentes.

Por outro lado, temos os casos contenciosos que decidem sobre situações concretas, possuem partes e litígio e, obviamente, uma pretensão de sentença. A sentença da Corte poderá reconhecer a responsabilidade internacional do Estado e instituirá medidas de reparação, compensação e satisfação.

Nesse sentido, Cardoso (2012, p. 91) ressalta que nos casos consultivos, apenas é possível a estratégia jurídica, pois a Corte não estabelece qualquer medida para cumprimento do Estado, já nos casos contenciosos são possíveis a estratégia jurídica e a de impacto social. As medidas de reparação individual nos casos contenciosos são consideradas parte do litígio tradicional e não do estratégico, pois este tem como característica transcender a decisão do caso concreto, buscando o máximo de repercussão social.

Por fim, a última fase corresponde a implementação da decisão por parte dos organismos domésticos dos Estados. A grande questão que se coloca nessa fase é a dificuldade do processo de implementação das decisões da Corte internalizado na estrutura institucional doméstica, isso ocorre pelas próprias dificuldades brasileiras como, por exemplo, o sistema federativo, dificuldades de ordem cultural, desconhecimento do sistema interamericano pela grande parte dos tomadores de decisão e a própria desvalorização do sistema no âmbito doméstico. 


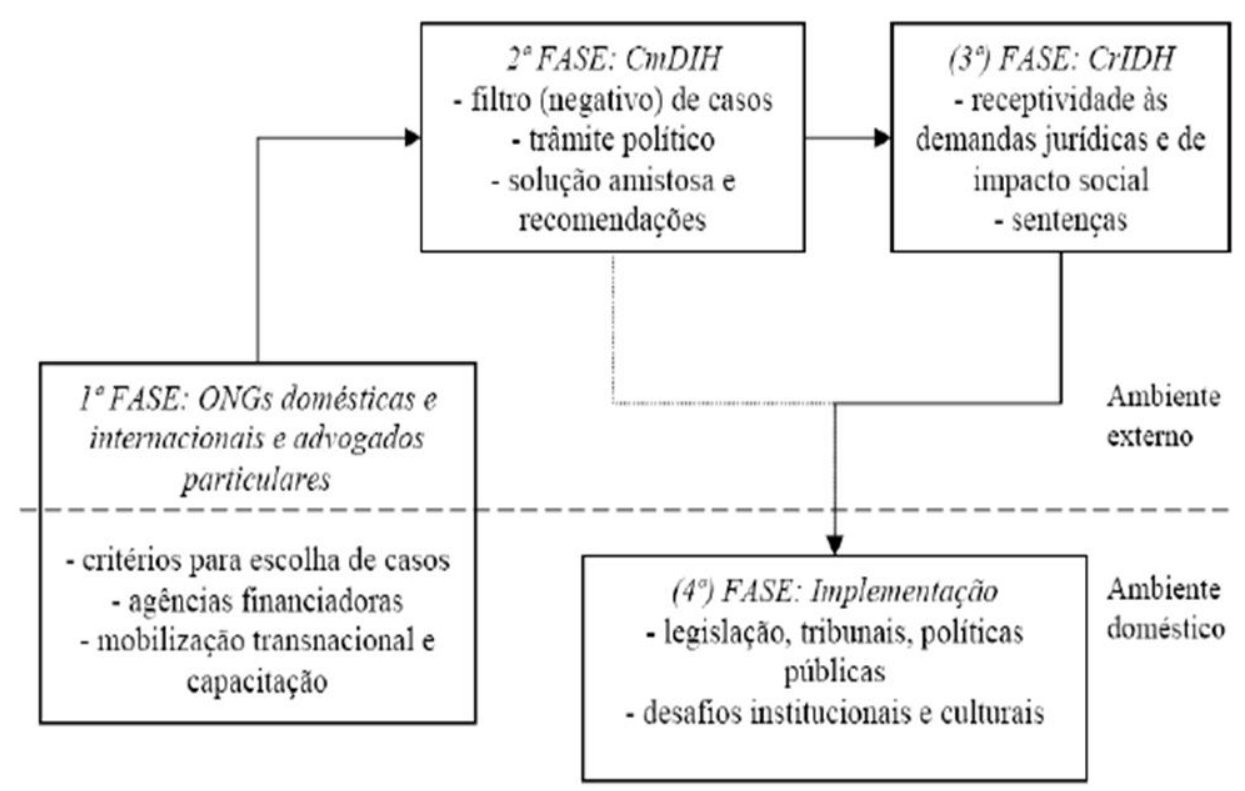

Figura 1 - Ciclo de vida do litígio estratégico no SIDH

Em síntese, é fundamental um movimento interno de cultura dos órgãos nacionais (Poderes legislativo, executivo e judiciário) para promover o respeito à normativa internacional. Tal qual ocorra um movimento externo reconhecendo a importância do sistema ao assegurar direitos no continente americano que foram violados, ou seja, o cumprimento das recomendações e sentenças advindas do SIDH.

Diante de todo o exposto, podemos observar que a globalização dos direitos humanos e a transnacionalização dos movimentos sociais têm contribuído para a expansão do ativismo jurídico transnacional. Como resultado desses processos, a $\mathrm{CIDH}$ tem ganhado mais credibilidade entre as ONGs de direitos humanos e pressionado os Estados membros da OEA a reconhecer e cumprir as normas de direitos humanos (SANTOS, 2007, p. 37) ${ }^{20}$. Resta evidente, que esse crescimento só está sendo em potencial, considerando as estratégias e as ferramentas utilizadas pelos atores sociais.

Contudo, não se pode negar que as estratégias do ativismo jurídico transnacional enfrentam dois tipos de limitações: primeiro, a mobilização jurídica apenas não é suficiente para promover mudanças sociais; segundo, as normas internacionais de direitos humanos

\footnotetext{
${ }^{20}$ Além disso, destaca a autora Cecília Santos que a credibilidade do SIDH entre as ONGs de direitos humanos e a avaliação positiva dos efeitos de suas decisões estão exemplificadas no seguinte artigo feito pelos membros do Centro para Justiça e Direito Internacional (CEJIL). AFFONSO, Beatriz; FREUND, Rita Lamy. Efeitos Práticos das Decisões dos Órgãos do Sistema Interamericano de Direitos Humanos. Disponível em: <https://www.social.org.br/relatorio2005/relatorio035.htm>. Acesso em: 12 mai. 2018.
}

DIGNIDADE RE-VISTA | ISSN2525-698X| 2020 | V. V | N. 9 ESP | Direitos Humanos, direitos para todos: pensando a igualdade material dos direitos. Pastoral Universitária Anchieta PUC-RIO. 
dependem dos Estados nação para o seu reconhecimento e cumprimento. Por depender das condições políticas locais, nacionais e internacionais, o Estado pode estar mais ou menos aberto a reconhecer tais normas (SANTOS, 2007, p. 50).

De fato, como é característico desse sistema jurídico possuir bases em dispositivos legais interpretados pelos tribunais competentes e que essas decisões dependam do Estado nação para o reconhecimento, visualizamos assim a figura do controle de convencionalidade ${ }^{21}$.

Não obstante, o objeto desse trabalho não versar sobre o controle de convencionalidade, a temática está diretamente relacionada a promoção de um litígio de impacto e a implementação do dever de interpretação desse standard da norma internacional ao ordenamento interno de cada país. Em linhas gerais, o controle de convencionalidade é um processo de verificação de (in)compatibilidade dos atos internos e normas jurídicas dos Estados-parte em relação aos tratados internacionais.

Nesse sentido, pode-se entender no dever conferido ao aparato estatal de zelar para que as disposições dos tratados internacionais de direitos humanos não sejam restringidas pela aplicação de leis nacionais contrárias ao objetivo fim da $\mathrm{CADH}$, ou seja, respeitar o exercício dos direitos e liberdades conferidos na Convenção, garantindo o seu livre e exercício sem qualquer discriminação alguma por motivo de raça, cor, sexo, idioma, religião, opiniões políticas ou de qualquer outra natureza, origem nacional ou social, posição econômica, nascimento ou qualquer outra condição social.

Isto posto, para a melhor compreensão desse standard interamericano, passar-se-á, em um capítulo próprio, à exposição e análise do caso Fazenda Brasil Verde vs. Brasil.

\section{Caso Trabalhadores da Fazenda Brasil Verde vs. Brasil}

Trata-se do primeiro caso de condenação de trabalho escravo decidido pela Corte IDH. Nela foi reconhecida a responsabilidade pelas violações de direitos de liberdade e ao direito de não ser submetido a qualquer forma de escravidão ou servidão, o direito de acesso à justiça, a garantias judiciais e o direito à razoável duração do processo das 85 vítimas escravizadas em 2000 na Fazenda Brasil Verde. Além do mais, a Corte IDH sustentou um marco de discriminação estrutural histórica, em razão da posição econômica, decorrente da pobreza e elevada concentração de propriedade de terra, bem como defendeu a natureza imprescritível do

\footnotetext{
${ }^{21}$ Sugestão do artigo do Valério de Oliveira Mazzuoli intitulado como Teoria geral do controle de convencionalidade no direito brasileiro. Disponível em: < http://www2.senado.leg.br/bdsf/item/id/194897>. Acesso em: 25 jun. 2018.
} 
crime de submissão de pessoas a condição análoga à de escravo (LEGALE; ARAÚJO, 2019, p. 161-162).

No entanto, é preciso esclarecer que não foi o primeiro caso denunciado ao SIDH de exploração de trabalho escravo na República Federativa do Brasil. A primeira denúncia encaminhada foi o caso José Pereira ${ }^{22}$, todavia, o desfecho internacional foi distinto do caso Fazenda Brasil Verde, uma vez que resultou em um acordo amistoso na $\mathrm{CIDH}^{23}$. Ressalto que, segundo o coordenador da Campanha contra Trabalho Escravo da CPT, Frei Xavier Plassat, a solução amistosa em 2003 foi considerada um divisor de águas pela influência decisiva que teve para o despertar de uma política nacional de erradicação do trabalho escravo ${ }^{24}$.

Feitas tais observações iniciais, iniciaremos a análise da responsabilização internacional do Brasil no caso Fazenda Brasil Verde, marcada pela interpretação diretamente relacionada ao art. 6.1 da CADH sobre a escravidão contemporânea.

Em primeiro lugar, importante destacar a atuação em parceria ${ }^{25}$ pelo Centro pela Justiça e o Direito Internacional (CEJIL) e a Comissão Pastoral da Terra (CPT) para encaminhar as violações ocorridas na Fazenda Brasil Verde, localizada no estado do Pará, no Brasil, de trabalho escravo ou análogo a escravo na CIDH com base no artigo 25 (1) e 40 da CADH. Posteriormente a análise da Comissão, o presente caso foi submetido em 4 de março de 2015 à Corte IDH, sendo a sentença proferida em 20 de outubro de 2016.

O cenário da Fazenda Brasil Verde foi, por muitos anos, de submissão dos empregados ao trabalho forçado em condições degradantes, com a restrição de sua liberdade, uma vez que não eram livres para ir embora, sendo mantidos presos na Fazenda sob ameaças e coação. Além disso, muitos trabalhadores ficavam submetidos àquela situação, por conta de uma suposta

\footnotetext{
${ }^{22}$ Nesta situação, em dezembro de 1994, as ONGs CEIL e Human Rights Watch apresentaram à CIDH reclamação denunciando a prática de trabalho escravo em condições análogas à de escravo no Brasil e, em especial, na Fazenda Espírito Santo (PA), à qual afluíram inúmeros trabalhadores, lubrificados por falsa promessas, entre eles o sr. José Pereira. Este, em especial, foi gravemente ferido e outro trabalhador rural foi assassinado, ao tentarem escapar do local em 1989. (...) De acordo com a CIDH, embora os agentes estatais não tivessem envolvidos nos eventos acima relatados, o Brasil deveria ser responsabilizado por sua omissão em prevenir a ocorrência de trabalho forçado e em aplicar sanções adequada aos culpados. Foram constatadas violações aos direitos à vida, à liberdade e à segurança pessoal, à proteção contra prisão arbitrária, à proibição da escravidão e da servidão, a um julgamento justo e a proteção judicial. Houve um acordo assinado pelas partes em dezembro de 2003 , que garantiu ao Sr. José Pereira o recebimento de indenização pelos danos sofridos, e também serviu para que o Brasil assumisse o compromisso de combater à escravidão em todo o território nacional. (AZEVEDO NETO, 2017. p.187)

${ }^{23} \mathrm{https}: / /$ cidh.oas.org/annualrep/2003port/Brasil.11289.htm

24 PLASSAT, Frei Xavier. Entrevista concedida a Thainá Mamede.

${ }^{25}$ Segundo o Frei Xavier Plassat, coordenador da Campanha contra Trabalho Escravo da CPT, a junção de esforços ocorreu uma vez que já existia uma experiência acumulada da CPT com o CEJIL no caso José Pereira.
}

DIGNIDADE RE-VISTA | ISSN2525-698X| 2020 | V. V | N. 9 ESP | Direitos Humanos, direitos para todos: pensando a igualdade material dos direitos. Pastoral Universitária Anchieta PUC-RIO. 
servidão por dívida e, devido à sua condição de extrema pobreza, isto é, sua situação de vulnerabilidade (CRUZ, 2018, p.53)

O perfil desses trabalhadores, em sua maioria, era de homens pobres, afrodescendentes ou mulatos, entre 18 e 40 anos de idade, recrutados em seus estados de origem por "gatos ${ }^{26 ",}$ para trabalhar em estados distantes, com a promessa de salários atrativos.

Importante destacar que a República Brasileira reconheceu em 1995 a existência e a gravidade do trabalho análogo à escravidão e implantou medidas estruturais de combate ao problema, como, por exemplo, a criação do Grupo de Fiscalização Móvel e a adoção de punições administrativas e criminais a empresas e proprietários. No entanto, tais medidas não foram efetivas, visto que nas fiscalizações os órgãos somente orientavam para que as "falhas" fossem corrigidas e normas trabalhistas cumpridas. Outra questão foi os impasses sobre os conflitos de competência de julgamento na jurisdição interna.

Em linhas gerais, a CIDH concluiu que o Brasil era responsável pelas violações de direitos humanos previstos nos artigos 1, $5,6,7,8,22$ e 25 da CADH, bem como dos artigos I, II, XIV, VIII e XVII da Declaração Americana de Direitos e Deveres do Homem. Reconheceu que não foram adotadas medidas para garantir que não houvesse mais discriminação dos trabalhadores mesmo após as fiscalizações ocorridas em 1993, 1996, 1997 e 2000, bem como destacou a imprescritibilidade de certos crimes. Desta forma, submeteu o caso à jurisdição da Corte IDH, com base no disposto no artigo 46.2 da CADH sobre as omissões estatais que ocorreram, ou continuaram ocorrendo posteriormente a 10 de dezembro de 1998, data de aceitação da competência da Corte pelo Estado, em conformidade ao artigo 62 da CADH.

A Corte IDH se julgou competente para conhecer e julgar a presente, analisou as dez exceções preliminares, bem como declarou parcialmente procedente a exceção preliminar interposta pelo Estado relativa à incompetência ratione temporis sobre os fatos anteriores à data de reconhecimento da jurisdição da Corte por parte do Estado e a incompetência ratione temporis em relação a fatos anteriores à adesão do Estado à Convenção Americana.

Destaca a Corte que trata de um primeiro caso contencioso perante o Tribunal Interamericano substancialmente relacionado com o inciso 1 do artigo 6 da CADH (CORTE IDH, 2016, p.63). Por essa razão realizou uma breve contextualização da evolução da matéria no âmbito do Direito Internacional para abarcar conceitos de escravidão, servidão, trabalho forçado, tráfico de escravos e mulheres sob a luz das normas gerais de interpretação prevista no artigo 29 da CADH e sobre os dispositivos relevantes. Ressaltou o caráter imperativo da norma

\footnotetext{
26 São aqueles responsáveis pelo recrutamento para o trabalho análogo à escravidão. DIGNIDADE RE-VISTA | ISSN2525-698X| 2020 | V. V | N. 9 ESP | Direitos Humanos, direitos para todos: pensando a igualdade material dos direitos. Pastoral Universitária Anchieta PUC-RIO.
} 
prevista no artigo 6.1 da $\mathrm{CADH}$, reafirmando como norma jus cogens, isto é, uma norma imperativa do Direito Internacional que implica em obrigação erga omnes, portanto, este dispositivo forma parte do núcleo inderrogável da $\mathrm{CADH}$. Em seguida, relatou que tanto o Brasil como a maioria dos Estados da região são parte dos principais tratados internacionais sobre esse tema específico: a Convenção sobre a Escravatura de 1926 e a Convenção Suplementar sobre a Abolição da Escravatura de 1956.

Merece destaque na sentença a afirmação de que os tratados de direitos humanos são instrumentos vivos, dado que o texto do tratado está sujeito aos efeitos do tempo. Assim é feita, uma interpretação evolutiva do tratado. Este é um método interpretativo utilizado frequentemente pela Corte IDH e também pela Corte Europeia de Direitos Humanos (Corte $\mathrm{EDH}$ ), quando é necessário recorrer ao contexto interno e/ou externo do tratado para se interpretar cláusulas ambíguas que sofreram efeitos da temporalidade. Trata-se de um método fundamental para as atividades desses tribunais, observadas as mudanças ocorridas nos direitos humanos ao longo as últimas décadas. Esse método é permitido pela Convenção de Viena sobre Direito dos Tratados (CVDT), em seu artigo 31. O conceito de interpretação evolutiva é desenvolvido com maior profundidade na sentença do caso Brasil Verde, enquanto que as menções ao artigo 29b e o princípio pro persona são breves e sucintas (LEGALE; ARAÚJO, 2019, p. 165-166).

Portanto, após a Corte ouvir a CIDH, as partes e os Estados, concluiu que estava configurada a violação ao artigo 6.1 da CADH e o artigo 149 do Código Penal Brasileiro. A aplicação decorre do fato que a legislação brasileira possui um tratamento mais favorável e protetivo as vítimas, restando clara a aplicação do princípio pro persona previsto no artigo 29 da CADH.

A Corte frisou que este conceito evoluiu e não mais se limita à propriedade sobre a pessoa. Portanto, passou a considerar que há dois elementos fundamentais para definir uma situação de escravidão (CORTE IDH, 2016, p.71). O primeiro elemento (estado ou condição) se refere tanto à situação de jure como de facto, isto é, não é essencial a existência de um documento formal ou de uma norma jurídica para a caracterização desse fenômeno, como no caso da escravidão chattel ou tradicional (CORTE IDH, 2016, p. 71).

Conforme o entendimento da Corte, o elemento de "propriedade" deve ser entendido como "posse", melhor dizendo, uma demonstração de controle sobre outra pessoa. Em outras palavras, quando há perda da própria vontade ou diminuição da autonomia pessoal (CORTE IDH, 2016, p. 72). O segundo elemento seria o chamado "exercício de atributos da propriedade", na qual como o controle exercido sobre uma pessoa com intenção de exploração 
mediante o uso, a gestão, o benefício, a transferência ou o despojamento de uma pessoa, podendo ser observado por meios de violência, fraude e/ou a coação (CORTE IDH, 2016, p. 72).

A Corte orientou que a análise da situação de escravidão nos dias atuais, deve-se averiguar os seguintes elementos: (i) restrição ou controle da autonomia individual; (ii) perda ou restrição da liberdade de movimento de uma pessoa; (iii) obtenção de um benefício por parte do perpetrador; (iv) ausência de consentimento ou de livre arbítrio da vítima, ou sua impossibilidade ou irrelevância devido à ameaça de uso da violência ou outras formas de coerção, o medo de violência, fraude ou falsas promessas; (v) uso de violência física ou psicológica; (vi) posição de vulnerabilidade da vítima; (vii) detenção ou cativeiro e; (viii) exploração.

No que corresponde à servidão, a Corte IDH coincide com a definição do Tribunal Europeu de Direitos Humanos, ponderando que essa expressão do artigo 6.1 da Convenção deve ser interpretada como "a obrigação de realizar trabalho para outros, impostos por meio de coerção, e a obrigação de viver na propriedade de outra pessoa, sem a possibilidade de alterar essa condição". Tal entendimento sobre a servidão corresponde a uma forma análoga de escravidão e deve receber a mesma proteção e obrigação que a escravidão em sua forma tradicional, isto é, proibição absoluta. Assim, com efeito, a Convenção Suplementar de 1956 definiu as formas análogas à escravidão como servidão, servidão por dívidas, entre outras formas.

Sabemos que a Convenção Americana proíbe tanto o tráfico de escravos como o tráfico de mulheres em todas as suas formas, de maneira que a Corte IDH interpreta essa proibição de forma ampla e sujeita às precisões de sua definição de acordo com seu desenvolvimento no Direito Internacional. Desse modo, o Tribunal faz um apanhado de conceitos incluídos nos tratados internacionais e de interpretações realizadas por outros tribunais internacionais de direitos humanos do que seriam as definições sobre tráfico de escravos como tráfico de mulheres.

Acerca do trabalho forçado ou obrigatório, ato proibido expressamente pelo artigo 6.2 da Convenção Americana, a Corte IDH reafirma que já se manifestou sobre o conteúdo e alcance desta norma no caso dos Massacres de Ituango vs. Colômbia. No presente caso, ficou estabelecido que a definição de trabalho forçado está prevista no artigo 2.1 da Convenção n. ${ }^{\circ}$ 29 da OIT. Ao final daquele caso, a Corte considerou que, para a cauterização de uma violação fosse atribuída aos agentes do Estado, deveria ser por meio de sua participação direta ou por sua aquiescência em relação aos fatos (CORTE IDH, 2016. p. 77). 
Nesse sentido, a Corte IDH constatou que: (i) os trabalhadores se encontravam submetidos ao efetivo controle dos "gatos", gerentes, guardas armados da fazenda, e, em última análise, também de seu proprietário; (ii) de forma tal que sua autonomia e liberdade individuais estavam restringidas; (iii) sem seu livre consentimento; iv) através de ameaças, violência física e psicológica, (v) para explorar seu trabalho forçado em condições desumanas. Além disso, as circunstâncias da fuga realizada pelos senhores Antônio Francisco da Silva e Gonçalo Luiz Furtado e os riscos enfrentados até denunciarem o ocorrido à Polícia Federal demonstram: (vi) a vulnerabilidade dos trabalhadores e (vii) o ambiente de coação existente nesta fazenda, os quais (viii) não lhes permitiam alterar sua situação e recuperar sua liberdade. Por todo o exposto, a Corte conclui que a circunstância verificada na Fazenda Brasil Verde em março de 2000 representava uma situação de escravidão (CORTE IDH, 2016. p. 79).

Portanto, trata-se de um caso de violações de vários direitos individualmente, no entanto, a Corte IDH interpretou que não é necessário fazer um pronunciamento individual a respeito de todos os direitos alegados pelos representantes, uma vez considerado caráter pluriofensivo da escravidão.

Explanou que a submissão de uma pessoa a esta condição, são violados vários direitos individualmente, alguns em maior ou menor intensidade, dependendo das circunstâncias fáticas específicas de cada caso. Em razão do exposto, os juízes reconheceram que o Estado violou as seguintes disposições da CADH: a obrigação de proteger direitos (art. 1), direito ao reconhecimento da personalidade jurídica (art. 3), o direito à integridade pessoal (art. 5), a proibição da escravidão, servidão e trabalho forçado (art. 6), o direito à liberdade pessoal (art. 7), o direito às garantias judiciais (art. 8), os direitos da criança (art. 19), o direito de livre circulação e residência (art. 22) e o direito à proteção judicial (art. 25).

Por fim, no que concerne as medidas e garantias de não repetição, a Corte fixou que a sua sentença constitui per se uma forma de reparação (CORTE IDH, 2016. p. 123), estipulou medidas que buscam reparar tanto o dano imaterial que não possui cunho pecuniário quanto “medidas de alcance” ou "repercussão pública” (CORTE IDH, 2016. p. 111).

Por conseguinte, estipulou algumas recomendações, determinando que: (i) publique o resumo oficial da presente sentença elaborado pela Corte, por uma única vez, no diário oficial, em um jornal de ampla circulação nacional e, a sentença integralmente, no período de um ano, em um sítio web oficial; (ii) adote, dentro de um prazo razoável, medidas legislativas necessárias para que a prescrição não seja aplicada à redução de pessoas à escravidão e suas formas análogas; (iii) pague os valores fixados na sentença, a título de indenização por dano imaterial, para cada um dos trabalhadores da Fazenda Brasil Verde, encontrados nas 
fiscalizações de 1997 e 2000; (iv) reembolso de custas e gastos dos representantes incorridos na tramitação do processo; e (v) reiniciar, com a devida diligência, as investigações e/ou processos penais relacionados aos fatos constatados em março de 2000, visando que, em um prazo razoável, identifique, processo e, se for o caso, puna os responsáveis.

Por fim, a Corte ressaltou que supervisionará o cumprimento integral desta sentença, no exercício de suas atribuições e na efetivação de seus deveres, conforme a Convenção Americana sobre Direitos Humanos. O caso somente será concluído, uma vez que o Estado Brasileiro cumpra tudo o que foi descrito na mesma.

\section{Conclusão}

No dia 13 de maio de 2018, completam-se 130 anos da abolição da escravatura com a Lei Áurea - resultado de movimentos sociais de luta e de resistência. Não se pode negar que ainda há muitos casos de trabalho escravo nas zonas rurais, como também ainda há casos de exploração nas zonas urbanas. Embora a escravidão pareça uma discussão antiga e sem fundamento, as raízes do escravismo brasileiro continua em sua dimensão política e social até os dias de hoje.

Os reflexos da escravidão ainda têm impactos profundos e significativos na sociedade. Uma grande herança da escravidão sentida até os dias atuais é a naturalização da desigualdade e, no Brasil, ainda tem relação a questão étnico-racial e sem nenhum pudor ainda sobrevive na sociedade, nas relações pessoais, nas relações de trabalho e nas instituições.

Necessário destacar a Organização Internacional do Trabalho (OIT) fundada em 1919, com objetivo da busca pela justiça social como condição para a paz permanente e contribuir com a promoção do trabalho decente no mundo. Ao longo dos anos, a OIT tem elaborado a partir de um processo de discussão tripartite protagonizado pelos governos, organizações de empregadores e de trabalhadores de seus Estados-membros as normas internacionais de trabalho.

O grande ponto de pesquisa desse trabalho foi compreender se ferramenta da litigância estratégica na arena do SIDH promoveu transformação externa e interna ao processo, isto é, se ocorreu a tematização do assunto e devolução do debate à sociedade, contribuindo para a erradicação do trabalho escravo e suas formas análogas. Em linhas gerais, podemos dizer que o litígio estratégico tem como objetivo modificar a realidade de violação de um direito e buscar 
a efetiva internalização dessa jurisprudência internacional no âmbito doméstico, bem como funcionar como standart para todo o sistema interamericano.

Resta inequívoco o corolário de que o instrumento da litigância estratégica foi utilizado no caso Fazenda Brasil Verde, na realidade podemos até considerar que ocorreu o uso da ferramenta do litígio de impacto na Solução Amistosa no caso José Pereira, uma vez que foi um relevante marco para o enfretamento ao trabalho escravo contemporâneo no Brasil, na qual resultou em diversos planos do governo de erradicação de trabalho escravo, criação da Comissão Nacional de Erradicação do Trabalho Escravo (CONATRAE), Pacto Nacional pela Erradicação do Trabalho Escravo, mudanças legislativas, lista suja, dentre outros.

Mas, mesmo assim não foi suficiente, haja vista que o cumprimento de sentença de uma responsabilidade internacional pela Corte IDH é um problema enfrentado por qualquer país. Logicamente, a submissão do caso Fazenda Brasil Verde já demonstra o quanto a realidade brasileira não buscou erradicar toda essa situação de discriminação estrutural histórica marcada pelas amarras da escravidão.

Acredito que a ferramenta do litígio estratégico bem estruturada pode repercutir forte e positivamente na garantia dos direitos humanos. No entanto, o real enfretamento do trabalho escravo no Brasil e em toda a América só será possível mediante cobrança de políticas públicas, atuação conjunta de prevenção, repressão ao crime e assistência às vítimas, de luta pelos nossos direitos e de cobrança para que o Estado cumpra com os seus deveres internacionais.

Ressalto que a sentença da Corte foi publicada em um momento político brasileiro conturbado (20 de outubro de 2016) e hoje em dia, ainda mais grave com o fim do Ministério do Trabalho e redução de verba para fiscalização. Outrossim, será sempre necessário resistir e lutar pelos nossos direitos e pelas condições mínimas de trabalho, mesmo quando a política do país está caminhando aos retrocessos.

Vale lembrar que, até 1995, o Brasil se recusava a reconhecer a existência de trabalho escravo no país. Anos depois, nós éramos referência para o mundo no combate à escravidão contemporânea. Não podemos perder isso. Reafirmo que o litígio estratégico não acaba com a sentença da Corte IDH, e sim serve como base para chamar atenção para aos abusos e violações de direitos humanos e de ressaltar a obrigação do Estado em cumprir com suas obrigações nacionais e internacionais. 


\section{Referências bibliográficas}

ABRAMOVICH, Victor. Das violações em massa aos padrões estruturais: novos enfoques e clássicas tensões no sistema interamericano de direitos humanos. In: SUR - Revista Internacional de Direitos Humanos. v. 6, n. 11, dez 2009. p. 6-39. Disponível em: $<$ http://www.scielo.br/scielo.php?pid=S1806-

$64452009000200002 \&$ script=sci_abstract\&tlng=pt $>$.

AZEVEDO NETO, Platon Teixeira de. A justiciabilidade dos Direitos Sociais nas Cortes Interamericanas de Justiça. São Paulo: LTr, 2017.

BERNARDES, Marcia Nina. Sistema Interamericano de Direitos Humanos como esfera Pública Transnacional: Aspectos Jurídicos e Políticos de Implementação de Decisões Internacionais. In: Revista SUR, v. 8, n. 15, dez. 2011. Disponível em: $<$ https://bdjur.stj.jus.br/jspui/bitstream/2011/46810/sistema_interamericano_direitos_bernardes. pdf $>$.

CARDOSO, Evorah Lusci Costa. Litígio Estratégico e o Sistema Interamericano de Direitos Humanos. Belo Horizonte: Editora Fórum, 2012.

CAVALLARO, J.L; SCHAFFER, E.J. 2004. Less as More: Rethiking Supranational Litigation of Economic and Social Rights in the Americas. 2004 apud BERNARDES, Marcia Nina. Sistema Interamericano de Direitos Humanos como esfera Pública Transnacional: Aspectos Jurídicos e Políticos de Implementação de Decisões Internacionais. In: Revista SUR, v. 8, no. 15, dez. 2011. $140 . \quad$ p. Disponível em:<https://bdjur.stj.jus.br/jspui/bitstream/2011/46810/sistema_interamericano_direitos_bern ardes.pdf

CRUZ, Thainá Mamede Couto da. A Litigância Estratégica como instrumento de combate ao Trabalho Escravo. Rio de Janeiro: 2018: 106p. Monografia de final de curso. Departamento de Direito da Pontifícia Universidade Católica do Rio de Janeiro - PUC-Rio.

INTERNATIONAL HUMAN RIGHTS LAW GROUP - IHRLG. Promoting Justice: A Practical Guide to Strategic Human Rights Lawyering. Washington: International Human Right Group, 2001. Disponível em: <http://www.sbdp.org.br/arquivos/material/280_IHRLG__International_Human_Rights_Law_Group_-_Promoting_justice__a_pratical_guide_to_strategic_HR_lawyering.pdf > .

LEGALE, Siddharta; ARAÚJO, Luis Cláudio Martins (Orgs). Direitos Humanos na prática interamericana. Rio de Janeiro: Lumen Juris, 2019.

MAZZUOLI, Valério de Oliveira. Curso de Direito Internacional Público. $7^{\mathrm{a}}$ ed. São Paulo: Editora Revista dos Tribunais, 2013.

MONTOYA, Lucas Correa. Litigio de alto impacto: Estrategias alternativas para enseñar y ejercer el Derecho. Opin. Jurid, v. 7, n. 14. Julio-Diciembre de 2008. Universid de Medellín. Disponível em: <https://revistas.udem.edu.co/index.php/opinion/article/view/161/145>

PIOVESAN, Flávia. Direitos Humanos e Justiça Internacional. 4ª ed. São Paulo: Saraiva, 2013. 
PRONER, Carolina. Sistema Interamericano de Direitos Humanos precisa ser reformado? Carta Maior. 2012. Disponível em: <https://www.cartamaior.com.br/?/Editoria/DireitosHumanos/Sistema- Interamericano-de-Direitos-Humanos-precisa-ser-reformado-/5/25281>.

SANTOS, Cecília Macdowell. Ativismo jurídico transnacional e o Estado: reflexões sobre os casos apresentados contra o Brasil na Comissão Interamericana de Direitos Humanos In: SUR - Revista Internacional de Direitos Humanos. v. 4, nº 7. São Paulo, 2007. Disponível em: $<$ http://www.scielo.br/scielo.php?pid=S1806$64452007000200003 \&$ script=sci_abstract\&tlng=pt $>$.

VILLARREAL, Marta. El litigio estratégico como herramienta del Derecho de Interés Público. In: MATUS, Fabián Sanchez. El litigio estratégico em México: la aplicación de los derechos humanos a nível práctico, experiencias de la sociedade civil. México: Alto Comissionado de las Naciones Unidas, 2007. p. 22. Disponível em: <https://www.hchr.org.mx/images/doc_pub/litigioestrategico.pdf>. 